\title{
Die narratiewe blikhoek in die mikrovertelling oor die genesing van die koninklike se seun deur Jesus in Johannes 4:43-54
}

\author{
Andries $\mathbf{G}$ van Aarde ${ }^{1}$ \\ Emeritus professor: Fakulteit Teologie \\ Universiteit van Pretoria
}

\begin{abstract}
Narrative point of view in the healing story of the official's son by Jesus in John 4:43-54

The article forms the third part of an essay that aims to introduce narratological codes applicable to the exegesis of New Testament texts. In the first article generic elements that constitute a narrative discourse were discussed. The focus was on aspects of intercommunicative nature. The aim of the second article was to explain how interactive relationships in a narrative discourse reveal the perspective from which a narrator presents a narration. From the perspective technically referred to as "narrative point of view", the present article applies the narrator's situation with regard to the role time, space, and characterization play in the poetics of a narrative to an exegetical analysis of John 4:43-54, focusing on the "narrator's ideological perspective" in John's gospel.
\end{abstract}

\section{INLEIDING}

\section{$1.1 \quad$ Vooropmerkings}

Die term "blikhoek" verwys in hierdie artikel na die mees dominante perspektief van waaruit die verteller in die Evangelie van Johannes die verhaal oor Jesus Christus aan sy eerste-eeuse lesers gekommunikeer het.

\footnotetext{
${ }^{1}$ Andries $\mathrm{G}$ van Aarde is Emeritus Professor in die Departement Nuwe-Testamentiese Wetenskap, Fakulteit Teologie, Universiteit van Pretoria. Hierdie artikel dien as 'n gevallestudie in opvolging van twee vorige artikels wat gefokus het op die eksegetiese teorie van narratiewe kritiek (kyk Van Aarde 2006a:657-677; 2006b:1111-1143). Hierdie artikels is met goedkeuring verwerkings in Afrikaans van 'n Engelse opstel, "Narrative criticism of the New Testament", wat in 'n bundel oor eksegetiese metodologie en hermeneutiek in die reeks Guide to the New Testament, Volume III, onder redaksie van A B du Toit deur Protea Publishing House uitgegee gaan word.
} 


\section{Die narratiewe blikhoek}

Vertellersperspektief en narratiewe blikhoek is dus in hierdie artikel uitruilbare terme. Wat die bedoelde lesers van die Evangelie van Johannes betref, het ons te doen met 'n gemeenskap wat al beskryf is as die "tweede generasie" volgelinge van Jesus wat hulle in 'n konteks aan die einde van die eerste eeu en begin van die tweede eeu nC bevind het (Duling \& Perrin [1974] 1994:409). Hierdie situasie was sterk beïnvloed deur die spanningsvolle verhouding tussen "Jesus-volgelinge" en "Moses-volgelinge" (Van der Watt 2005:105-106, 128). Laasgenoemde het sinogogale strukture as vervangende replisering van 'n tempelideologie daar begin stel (vgl Moloney 1998:2-6). So 'n "beleid" was daardeur genoodsaak dat die dominansie van die Jerusalemse tempel tot 'n einde gekom het met die vernietiging daarvan deur die Romeine (vgl Martyn 2003:40, 89; Waetjen 2005:37).

Die dominante narratiewe blikhoek in die Evangelie van Johannes word deur frases geartikuleer soos om te "sien" en te "glo" (bv Joh 20:8; 20:24-25, 28-29) (vgl Dunn [1977] 2006:27-30). Onder die karakters wat in die Johannese narratief vermeld word, is die ongelowige Tomas by uitstek ' $n$ voorbeeld van een wat al struikelend glo op grond van wat dat hy gesien het. Die Geliefde Dissipel blyk die ideale karakter te wees. Hy konformeer ten volle met die teologiese vertellersperspektief. ${ }^{2}$ Die spanningsbelaaide interaksie tussen Petrus en die Geliefde Dissipel in Johannes 21 sorg vir 'n dramatiese oop-einde aan die einde van die plot van die Evangelie - wat ontvou in die verloop van die vertelling. Aan die einde van die geskrewe Evangelie word die verhaal voortgesit in die lewe van die gemeenskap vir wie Johannes sy verhaal geskryf het.

Die bedoeling van hierdie artikel is om te illustreer hoe bogenoemde narratiewe blikhoek tot uitdrukking kom in die mikrovertelling oor die genesing van die koninklike se seun deur Jesus in Johannes 4:43-54. Die verwysing na die herhaling van 'n "teken" (ớpદiov) in Johannes 4:54 verbind Jesus se eerste wonderwerk by die bruilof in Kana (Joh 2:1-12) met die tweede genesing, dié van die genesing van die koninklike se seun (Joh 4:43-53). Dit verbind ook al sewe wonder-"tekens" in Johannes se narratief van Jesus. Eksegete is van oordeel dat die nommering van "tekens" daarop dui dat die verteller met 'n bepaalde doel voor oë al sewe die wondertekens in Johannes se narratief met mekaar verbind (kyk o a Thacher 2000:24-34).

Bogenoemde dominante blikhoek word in die narratief gekommunikeer teen die agtergrond van die kwessie of die dissipels (en die lesers) in staat sal

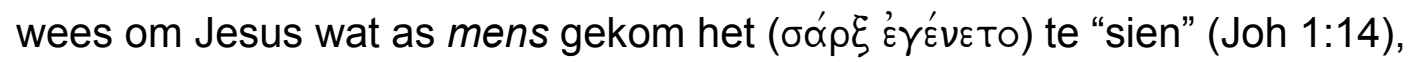

\footnotetext{
${ }^{2}$ Kyk Van Aarde, A G 1985, Die outeurskapsvraag van die Johannesevangelie met die oog op interpretasie of resepsie; Van Aarde, A G 1991, Narrative criticism applied to John 4:4354.
} 


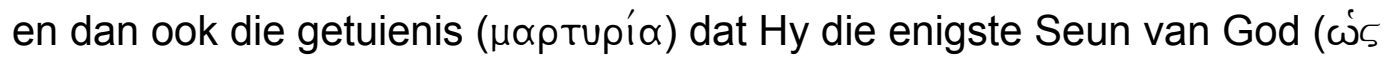

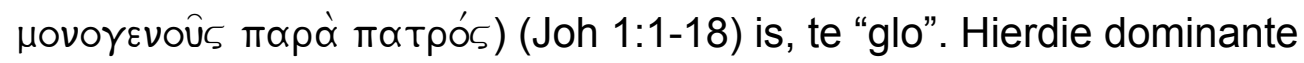
uitgangspunt word regdeur die evangelie deur die vertelling van sewe wondertekens (sēmeia) geopenbaar. Johannes se oop-einde is in 'n sekere sin 'n herhaling van die begin: "Ja, Jesus het ook baie ander tekens in die teenwoordigheid van sy dissiples gedoen - [tekens] wat nie in hierdie boek neergeskryf is nie. Hierdie tekens is beskryf sodat julle kan glo dat Jesus die Christus, die Seun van God is en sodat julle, deurdat julle glo, die lewe in sy naam kan hê" (Joh 20:30-31; my vertaling). Johannes se beginwoorde is onder andere dat die die lewe te vind is in die Logos wat mens geword het en dat dié lewe die lig vir die mense is (Joh 1:1-5).

Die onderhawige artikel is die derde in 'n reeks wat bedoel is om as inleiding tot narratief-kritiese eksegese van Evangeliemateriaal te dien. Die eerste artikel (Van Aarde 2006a) het gefokus op die genre-kenmerke van narratiewe tekste en die tweede artikel (Van Aarde 2006b) op die wyse waarop "narratiewe blikhoek" (narrative point of view) aspekte soos karakterisering beïnvloed, asook die tydsdimensies van 'n narratief en die rol wat plekke daarin speel. In die onderhawige artikel word die inhoud van beide die vorige twee artikels prakties toegepas op die eksegese van 'n mikrovertelling, te wete dié oor die genesing van die koninklike se seun deur Jesus in Johannes 4:43-54. Op grond van die erns maak van die aspek "genre" (eerste artikel) word daar eerstens (eerste afdeling van derde artikel) gevra of die betrokke mikrovertelling wel as 'n narratief gesien kan word. Die erns maak met narrative point of view (tweede artikel) lei vervolgens tot eers 'n analise van die "oppervlaktestruktuur" (tweede afdeling van derde artikel) en daarna 'n analise van die "dieptestruktuur" (derde affdeling). Die "oppervlaktestruktuur" het te doen met eerstens die possisie van die verteller in die verhaal en tweedens die narratiewe diskoers self, bestaande uit karakterontleding en 'n ondersoek na tyd en ruimte in die verhaal. Die "dieptestruktuur" het te doen met wat in die teoretiese uiteensetting in die tweede artikel die "ideologiese perspektief" van die verteller genoem is. Die vertellersperspektief is dié dieper liggende perspektief wat tot uitdrukking kom in die interaksies van karakters wat op die "oppervlakte" van die verhaalstruktuur in terme van 'n bepaalde struktuur van tyd en ruimte figureer. Die artikel word met 'n bevinding ten opsigte van die dominante narratiewe blikhoek van die betrokke mikrovertelling afgesluit.

\section{IS JOHANNES 4:43-54 'N NARRATIEF?}

Johannes 4:43-54 is om twee ooglopende redes 'n narratief. Die diskoers is georden volgens karakters (soos bv Jesus en die koninklike amptenaar) wat 
binne 'n bepaalde struktuur van tyd en ruimte (soos bv die ruimte tussen Samaria en Galilea) beweeg en daar is 'n chronologiese opeenvolging van episodes in 'n kousale verhouding (plot) (die tog na Kana, die ontmoeting met die regeringsamptenaar en die slot).

\section{ANALISE VAN DIE "OPPERVLAKSTRUKTUUR"}

\subsection{Die vertellersituasie}

\subsubsection{Eerstepersoons- of derdepersoonsnarratief?}

Johannes 4:43-54 is 'n derdepersoonsvertelling, dit wil sê 'n verteller van buite die teks verwys in die derde persoon na die karakters in die narratief. Alhoewel sommige van die karakters deur middel van direkte rede kommunikeer, verander die verteller se blikhoek nie.

\subsubsection{Die verteller se ruimtelike situasie}

In Johannes 4:43-54 neem die verteller beide 'n alwetende en 'n beperkte blikhoek aan. Vanuit 'n ruimtelike perspektief blyk die alwetende blikhoek uit verwysings na die Galileërs wat die Paasfees in Jerusalem bygewoon het (vers 45). Die verteller meld dat feitlik almal in Judea of in Galilea - met die uitsondering van die hoofkarakter, Jesus, se "eie mense" wat Hom nie as 'n profeet geëer het nie - geweet het dat Jesus wonderdade doen. Die beperkte blikhoek weer, kom baie duidelik na vore ná vers $46 \mathrm{~b}$, veral in die persoon van die koninklike amptenaar. Hy ontmoet Jesus in Kana, maar weet nie van die wonderwerk wat vroeër in Kapernaum plaasgevind het nie.

Die rede vir die gebruik van die tegniek van 'n beperkte blikhoek het moontlik daarmee te doen dat die verteller verwag dat die implisiete leser met die koninklike as karakter moet assosieer. Die dissipels (asook die lesers wat met hulle assosieer) word dikwels in die Evangelie van Johannes uitgebeeld as mense wat insig behoort te gehad het, maar in realiteit slegs beperkte kennis het (kyk bv Joh 14:4-7; 16:17-18). Afgesien van die regeringsamptenaar, dien Jesus ook as die "voertuig" vir die verteller se ideologiese perspektief.

\subsubsection{Die "emotiewe" situasie van die verteller}

Die alwetende blikhoek van die verteller kom duidelik na vore vanaf vers 44: "Hy het self verklaar ..." teenoor die beperkte blikhoek in vers 50: "Die man het geglo ..." 


\subsection{Die narratiewe diskoers}

\subsubsection{Tyd}

\subsubsection{Verhalende tyd}

Johannes 4:43-54 bestaan uit twaalf verse. Verse 1 tot 4 vertel van Jesus se reis van Samaria en toe van Kana na Galilea. In die daaropvolgende agt verse volg 'n statiese gedeelte wat oor die ontmoeting tussen Jesus en die amptenaar handel.

\subsubsection{Verhaalde tyd as "storietyd"}

Die begin van die storie strek van Johannes 4:43 tot 44, die gedeelte waarin van Jesus se reis vanaf Samaria na Galilea vertel word. Die middelste gedeelte strek vanaf vers 45 tot vers 53 en bevat twee tonele, die eerste gaan oor Jesus se aankoms in Galilea en word gevolg deur sy besoek aan Kana. Die aankoms van die koninklike amptenaar in Kana en sy ontmoeting met Jesus vorm die tweede toneel. Hierdie gedeelte, wat van verse $46 \mathrm{~b}$ tot 53 strek, kan weer in twee kleiner tonele opgedeel word, naamlik die ontmoeting in Kana, gevolg deur die koninklike se terugkeer na sy huis in Kapernaum en dít wat onderweg na en in Kapernaum gebeur het. Die storie eindig met vers 54 waarin daar uitgewys word dat Jesus se tweede wonderwerk ook in Kana plaasgevind het.

Verhaalde tyd word soms met "besprochene Zeit" (kyk tweede artikel) afgewissel, soos byvoorbeeld in die geval van vers 44 waar daar deur middel van kommentaar na die Judeërs se antagonisme verwys word. Dit geld ook die verwysing in vers 45 na hoe die Galileërs Jesus ontvang het. Die rede wat vir hulle positiewe gedrag aangevoer word, is dat hulle ook die Paasfees bygewoon het en Jesus se wonderdade van God se genesing van gemarginaliseerdes gesien en ervaar het. Dieselfde geld ook vir vers 46 wat 'n verwysing na die eerste wonder(teken) in Kana bevat. Vers 54 sinspeel op die genesing van die amptenaar se seun as die tweede wonder(teken).

\subsubsection{Verhaalde tyd as "geplotte tyd"}

Die "storie" (histoire) in Johannes 4:43-54 bestaan uit die volgende episodes:

- Die aankoms in Galilea.

- Die ontvangs in Galilea.

- Die aankoms in Kana.

- Die ontmoeting met die amptenaar.

- Die reis na Kapernaum.

- Konklusie. 


\section{Die narratiewe blikhoek}

Ten einde die ideologiese perspektief, wat die chronologie en kousaliteit van bogenoemde episodes bepaal te identifiseer, moet mens kyk na afwykings vanaf hierdie liniêre sekwensie. Wat die oorgang van die eerste na die tweede episode betref, is Jesus se verwysing na sy eie land 'n sinspeling van 'n spanningssvolle kontras tussen Judea en Galilea.

Alhoewel Jesus as profeet in Judea verwerp word (Joh 4:44), word Hy in Galilea verwelkom (Joh 4:45). Die gedeelte wat in die "besprochene Zeit" hierop volg, naamlik Jesus se handeling tydens die Paasfees wat as rede vir sy hartlike ontvangs aangevoer word, is 'n sinspeling op 'n verdere aspek. Dit het naamlik betrekking op Jesus se latere woorde aan die Galileërs oor die "sien van tekens en wonders" as "voorvereiste" vir geloof. ${ }^{3}$ Terselfdertyd is hierdie woorde ook 'n heenwysing na vorige kommentaar van die verteller in Johannes 2:23-25. In laasgenoemde gedeelte word berig dat, hoewel baie tot geloof in Jesus gekom het, omdat hulle die wondertekens gesien en ervaar het wat Hy tydens die Paasfees in Jerusalem gedoen het, Jesus nie vertroue in hulle gestel nie.

Jesus se vertrek vanaf Judea na Kana is as afwyking vanaf die liniêre tyd van die wyer verhaal eweneens belangrik. Die feit dat die verteller Jesus se tweede wonder ("teken") met Kana verbind, is beduidend. In die loop van die plot word daar van 'n totaal van sewe wonders ("tekens") vertel.

Die spanning bou op soos wat die verteller se ideologiese blikhoek rondom die fraseologie met betrekking tot die uitdrukkings "sien" en "glo" in die verloop van die plot van die hele Johannese narratief ontwikkel. Die wonderwerke ("tekens") het geloof in Jesus of verwerping van Jesus as respons tot gevolg. Die storie van die "ongelowige Tomas" sluit die dénouement af. In hierdie episode hoor ons die opmerking van die opgestane Jesus dat diegene wat glo sonder dat hulle gesien het, geseën is. Hierdie episode loop uit op 'n oop-einde (kyk Van Aarde 2006a:671-672) en skep 'n uitdagende vraag aan die implisite leser: hoe sou jy op die vertelling van elkeen van die sewe wonders ("tekens") in die Evangelie van Johannes as geheel reageer? Die heenwysing na Jesus se eerste wonderwerk ("teken") wat aan die einde van die storie oor die genesing van die koninklike se se seun deur Jesus voorkom - dui op 'n gedeelde herinnering wat die leser weer 'n keer in onder andere die verhaal van die "ongelowige Tomas" verneem.

In die betrokke mikrovertelling in Johannes 4:43-54 word pertinent gemeld dat Kana 'n plek in Galilea is (vers 46). Dit bevestig die Jesus-tradisie (vgl ook die Sinoptiese Evangelies) dat Galilea nie alleen die ruimte is waar Jesus sy wonderwerke doen nie, maar dat dit ook funksioneer as fokale

\footnotetext{
${ }^{3}$ Vergelyk Gilbert van Belle (1988), "The faith of the Galileans: The parenthesis in Jn 4,44".
} 
ruimte. Die Galileërs se ideologiese perspektief, naamlik dat hulle 'n waarderende houding teenoor Jesus inneem, word daardeur aangetoon. Die wyse waarop die Galileërs Jesus ontvang (vers 45), in kontras met die verwerping van Jesus deur die Judeërs (vers 44b), is gebaseer op die Galileërs se sien en ervaring van die wonders ("tekens"). Die eerste insident in Kana (Joh 2:1-12) beklemtoon insgelyks Maria (Jesus se ma) se onvoorwaardelike geloof in Jesus se woorde, soos wat die geval met die koninklike amptenaar in die tweede insident in Kana (Joh 4:43-54) is.

Wanneer daar na die "verhaalde tyd" van die daaropvolgende twee episodes, wat sewe uit die twaalf verse beslaan, gekyk word, is dit duidelik dat hierdie gedeelte van groot belang vir die narratief is. Twee volledige narratiewe lyne (Handlungssträngen- kyk tweede artikel) kan in hierdie geval geïdentifiseer word:

\section{Die eerste narratiewe lyn}

- Die koninlike amptenaar vertrek vanaf Kapernaum na Jesus toe nadat hy gehoor het Jesus is in die omtrek en doen dit omdat sy kind siek is (begin).

- $\quad$ Dit word gevolg deur die gesprek tussen Jesus en die koninklike amptenaar (middel).

- $\quad$ Dit eindig met die vermelding dat die koninklike amptenaar Jesus glo en huis toe gaan (einde).

\section{Die tweede narratiewe lyn}

- $\quad$ Die koninklike amptenaar ontmoet sy slawe (begin).

- Dit word gevolg deur die gesprek tussen die koninklike amptenaar en sy slawe (middel).

- $\quad$ Dit eindig met die vermelding dat beide die koninklike ampternaar én sy huishouding glo (einde).

Saam gesien, hou die twee narratiewe lyne 'n bepaalde spanning in. Beide narratiewe lyne eindig met 'n vermelding dat karakters tot geloof gekom het. Die klimaks van die eerste narratiewe lyn is die vermelding van die koninklike amptenaar se kom tot geloof in Jesus se woorde. Die klimaks van die tweede narratiewe lyn is ' $n$ herhaling van die koninklike se geloof maar wat daarby vermeld word, is dat sy huishouding op grond van die koninklike se woorde saam tot geloof gekom het.

Die werkwoord "glo" bied geen aanduiding of die een geval van "geloof" (vers 50) in die eerste narratiewe lyn die ander geval van "geloof" (vers 53) in die tweede narratiewe lyn óf uitsluit óf aanvul nie. 
Die eerste insident het in Kana plaasgevind en die daad van glo vind plaas sonder dat die koninklike as vader van die sterwende seun kon sien dat Jesus die seun, wat in Kapernaum was, genees het. Die vermelding van die koninklike se geloof in die eerste narratiewe lyn dien dus as 'n voorbeeld van geloof sonder die sien van sigbare "tekens". Dieselfde "gebeure" word in die wyer plot van die Evangelie van Johannes aangetref in eerstens die geval van die Geliefde Dissipel by die leë graf (Joh 20:8) en tweedens die geval van die Jesus-volgelinge wat na die opgestane Jesus se gesprek met die "ongelowige" Tomas (Joh 20:29) deur Jesus geseën en geprys word.

Vanuit 'n narratiewe oogpunt, wat tydsdimensie betref, is die idee van "sien" en "glo" 'n voorbeeld van dít wat in die tweede artikel met betrekking tot narratiewe blikpunt op temporale vlak frekwensie genoem is. Dit is 'n idee wat by herhaling in die wyer plot van die Johannese narratief voorkom. In die tweede artikel (Van Aarde 2006:1111-1143) het ek daarop gewys dat "reëlmaat" te make het met herhaling en dat die herhaling van 'n idee 'n belangrike bousteen van 'n storie se plot is en spanning skep.

Die vraag wat hier ten opsigte van die herhaling van die kom tot geloof in beide narratiewe lyne ontstaan, is dié na die aard van die verhouding tussen die twee "glo's" in die mikrovertelling oor die genesing van die koninklike se seun deur Jesus in Johannes 4:43-54. Behoort die eerste daad van glo geringer geag te word as die een wat volg op die sien en ervaar van sigbare "tekens"? So gesien, moet die tweede "glo", ten einde "ware" geloof te kan wees, deur die eerste genoemde "glo" aangevul word. ${ }^{5}$ Het die koninklike aanvanklik net geglo dat sy seun genees is en eintlik eers nadat hy die wonderwerk self ervaar het en as gevolg van daardie gewaarwording geglo het dat Jesus die Seun van God is?

Dit wil egter voorkom of die Verknüpfungsprinzip (die aanknopingspunt, d w s nexus) tussen die parallelle narratiewe lyne mekaar nie opponeer nie, maar eerder analogies is. ${ }^{6}$ Dit wil voorkom of die tweede lyn die eerste een bevestig. Dit is egter nie net 'n kwessie van blote bevestiging nie. Die verteller

\footnotetext{
${ }^{4}$ Francis Moloney (1998:154) stel dit soos volg: "The verb pisteuein opens the sentence. The man believed, and the object of his belief is the word that Jesus had spoken to him (tō logō hon eipen autō ho lēsous). There are no 'signs and wonders' supporting this belief. The official does not fall under the judgment of v. 48. Jesus had commanded him, 'Go (poreuou), your son is living' (v. 50a). The response of the man closes with a wordless acceptance of the command of Jesus: 'and he went (eporeueto)' (v. 50b)."
}

5 So Barnabas Lindars (1972:204): "This [die vermelding van geloof in die tweede narratiewe lyn] is the true kind of belief, by contrast with verse 48."

6 So Rudolf Bultmann ([1941] 1971:208): "The reason why the father does not simply confirm the healing on his return home, but has to be told the news of the cure on the way by his servants, is that they cannot know the reason for the cure and are thus beyond suspicion as witness." 
se dominante blikhoek word duidelik. Geloof behels meer as die aanvaarding van Jesus as die doener van wonderwerke ("tekens"), die rede waarom die Judeërs Jesus verwerp het en die Galileërs vir Jesus ontvang (aanvaar?) het.

Die einde van die mikrovertelling oor die genesing van die koninklike se seun verteenwoordig 'n verdere afwyking van die liniêre chronologie van gebeure as gevolg van die vertellerskommentaar wat dit met die vorige verwysing na Kana, waar die eerste wonder ("teken") plaasgevind het (2:1$12)$, in verband bring.

In die inleiding van die artikel het ons reeds daarop gewys dat die motief van wonderwerke ("tekens") in die Evangelie van Johannes dien as 'n bevestiging van die ware identiteit van Jesus as God wat mens geword het

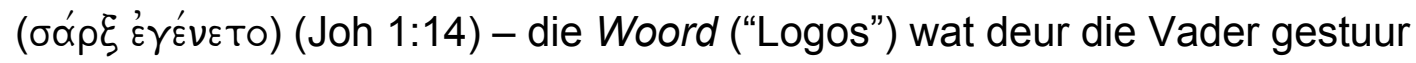
is, die "Logos" wat tegelykertyd goddelik en menslik is. In Johannese terme beteken geloof dat die hindernis (Anstoß) waarvolgens Jesus slegs maar as buitengewone mens beskou word - dit wil sê 'n "wonderdoener" soos die Galileërs vir Jesus gesien, ervaar en daarom in hulle midde ontvang het (vgl Moloney 1998:153).

Die geloof wat Johannes egter in gedagte gehad het, is volgens hom alleen moontlik indien daar by die "fisikaliteit" van Jesus van Nasaret verby beweeg word - dit wil sê verby die fisiese Jesus wat fisies mense op wonderbaarlike wyse deur fisiese genesings help en ondersteun; nie bloot die ervaring en erkenning van Jesus as mens ("en sarki") nie, maar ook die glo in die geestelike Jesus as die Woord ("Logos") van God. In die verhaal oor die genesing van die koninklike se seun deur Jesus kom geloof neer op die glo van die "woord" van Jesus sonder om fisiese "tekens" te sien; 'n glo dat Jesus "logos in vlees/sarki" is (vgl Moloney 1998:155). ${ }^{7}$

En synde gestuur, soos wat die geval was (in uitgedruk deur die

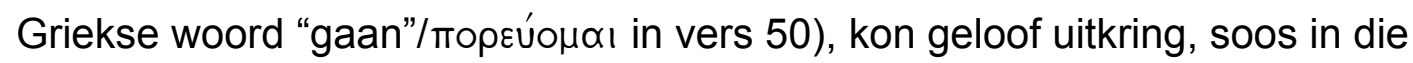
geval van die huishouding van die koninklike amptenaar. Die koninklike en ander kom tot geloof. Die "glo" in die tweede narratiewe lyn is dus nie 'n geloof van hoër kwaliteit as die "glo" in die eerste narratiewe lyn nie. Hier is sprake van uitkringende geloof - geloof in die "woorde" van Jesus en dan in die "woorde" van diegene wat gelowig ander op hulle pad ontmoet. En hierdie geloof is die tipe geloof wat in Johannes 20:29 geprys word, omdat dit nie op "sien" van die fisiese opgestane Jesus gebaseer is nie maar ten spyte daarvan dat ons alleen die "getuienis"/"woorde" oor dié Jesus het. ${ }^{8}$

\footnotetext{
${ }^{7}$ Moloney (1998:157) vat dit soos volg saam: "At Cana a Gentile official demonstrates faith in the word of Jesus and initiates a process that leads to a miracle, his recognition of the authority of the word of Jesus and the belief of his household."

${ }^{8}$ Vergelyk Francis Moloney (1993), Belief in the Word: Reading John 1-4, pp 168-175.
} 


\section{Die narratiewe blikhoek}

\subsection{Ruimte}

Jesus het van Sigar in Samaria na Galilea, waar Hy hartlik ontvang is, gegaan. Beide Galilea en Judea, waar Hy nie welkom was nie, dien as fokale ruimtes. Dit is tekenend van die atmosfeer waarbinne die storie plaasvind. Daar is 'n kontras: 'n antagonistiese Judea teenoor 'n ontvanklike Galilea.

Kana dien as fokale ruimte, want dit is daar waar die eerste wonder ("teken") plaasgevind het. Die feit dat later weer na Kana verwys word, skep 'n gespanne afwagting. Die water wat in wyn verander word, kan as 'n voorbeeld van ruimtelike bykomstigheid geag word (kyk tweede artikel; Van Aarde 2006:1111-1143). Die afstand tussen Kana en Kapernaum dien as fokale ruimte wat 'n aanduiding is daarvan dat die wonder("teken") oor 'n afstand heen plaasgevind het.

Gesien vanuit die perspektiewe soos deur die karakters in die onderskeie fokale ruimtes (Galilea en Samaria teenoor Judea) verteenwoordig, blyk sommige karakters, met die uitsondering van die inwoners van Judea wat teenkanting toon, dieselfde standpunt as die verteller te huldig. Hierdie tendense hou verband met óf hulle aanvaarding óf verwerping van Jesus. Die feit dat die wonderwerk oor afstand heen geskied het, bring 'n belangrike kwessie na vore, naamlik dié van geloof sonder sigbare tekens.

\subsection{Karakterisering}

Jesus is die protagonis in die narratief, die inwoners van Jerusalem die antagoniste en die inwoners van Galilea (met inbegrip van die koninklike amptenaar) die helpers. Die protagonis dien as "voertuig" vir die verteller se dominante blikhoek.

Ander voorbeelde van naamgewing speel ook 'n rol. In vers 44 word Jesus as 'n profeet beskryf. Volgens die vertellersperspektief word Jesus se "ware" identiteit regdeur die Evangelie van Johannes egter beskryf as synde die een wat "van bo kom" en "nie van onder" is nie (kyk Joh 3:31). Dit is juis hierdie insig in Jesus se "ware" identiteit wat in die plot van die Johannese narratief die Anstoß vorm wat die Judeërs nie kon oorkom nie. Ten beste is Jesus deur sommige as "profeet" erken (vgl Joh 7:40). Ander Judeërs het so 'n moontlikheid openlik verwerp (vgl Joh 4:44 met Joh 7:41). Omdat Jesus van Galilea was (Joh 7:41), kon hulle Hom nie as God se Messias erken nie. Die Samaritane het Hom wel as die "verlosser" aanvaar (Joh 4:25-26) - nie alleen as die "verlosser van Israel" nie (Joh 4:22), maar as die "verlosser van die wêreld" (Joh 4:42). Die Galileërs het Jesus weliswaar ook aanvaar (Joh 4:45), maar slegs as "doener van wonderwerke" (Joh 4:48). 
Die benaming "koninklike amptenaar" ( $\beta \alpha \sigma ı \lambda ı$ ı́́s, vers 46) beklemtoon dat hierdie Galilese amptenaar in diens van die Herodiaanse hofhouding ${ }^{9}$ in die oë van die Judeërs en hulle leiers 'n uitgeworpene was (net soos die Samaritane waarvan daar in die vorige perikoop vertel is; vgl Moloney 1998:156). Die amptenaar het egter as "helper" van die protagonis teen die antagoniste opgetree. As 'n Galileër het hy (net soos Maria en Johannes die Doper in 'n bepaalde Israelse situasie vroeër in die Evangelie van Johannes en soos die Samaritaanse vrou in 'n universele, nie-Israelse situasie) ${ }^{10}$ die Anstoß oorkom en het in Jesus geglo. Die amptenaar se geloof was enersyds nie afhanklik van die waarneming van wonderwerke nie en andersyds het hy dit verder uitgedra deurdat sy ganse huishouding daarin kon deel.

\section{DIE IDEOLOGIESE PERSPEKTIEF}

In die vorige artikel (Van Aarde 2006:1111-1143) het ek uitgewys dat die konsep "ideologie" verwys na die netwerk van temas en idees wat binne 'n narratief voorkom. Die ideologiese perspektief in die narratief is die dominante blikhoek van waaruit die verteller alle elemente in die verhaal aanbied met die doel dat die lesers/hoorders van die narratief op so 'n wyse daardeur "gemanipuleer" sal word dat hulle met die betrokke ideologiese uitgangspunt sal saamstem of dit dan verwerp. Op grond van die voorafgaande ontleding kan volgende netwerk van temas in die mikrovertelling oor die genesing van die koninklike se seun in Johannes 4:43-54 geïdentifiseer word:

- In kontras met die antagonisme in Judea, word Jesus in Galilea hartlik ontvang.

- $\quad$ Die wonderwerk hou verband met die eerste wonderwerk op dieselfde plek.

- $\quad$ Die wonderwerk geskied oor afstand heen.

- Die aanvaarding van geloof sonder die ervaring van sigbare tekens en wonders.

- $\quad$ Volgens die Evangelie van Johannes dien sigbare tekens en wonders slegs as bevestiging van Jesus se "ware" identiteit (vgl 3:2). Jesus se woorde is dus op sigself geloofwaardig.

\footnotetext{
${ }^{9}$ Volgens Uwe Wegner (1985), Der Hauptmann von Kafarnaum (Mt 7,28a; 8,5-10.13 par Lk 7,1-10): Ein Beitrag zur Q-Forschung, pp 60-69, was die koninklike amptenaar waarskynlik 'n "heiden", byvoorbeeld 'n Romein. Moloney (1998:160) oordeel egter: "The context, and the widespread use of the term in Josephus ... suggest that the charachter in the Johannine story is a soldier of either the Herodian kings or of the emperor."

${ }^{10}$ Kyk Francis Moloney (1980), "From Cana to Cana (Jn 2:1-4:54) and the Fourth Evangelist's concept of correct (and incorrect faith)".
} 


\section{BEVINDING}

Die verteller se dominante narratiewe blikhoek kan soos volg opgesom word: Jesus behoort in geloof aanvaar te word en behoort as die Seun van God beskou te word. Geloof is die resultaat van die aanhoor van woorde sonder dat tekens en wonders noodwendig aanskou word. Die koninklike amptenaar word vanuit 'n analogiese perspektief aangebied en die inwoners van Judea (Jerusalem) vanuit ' $n$ kontra-perspektief. Die protagonis (Jesus) se perspektief kom ooreen met dié van die verteller. Die implisiete leser word "gemanipuleer" om hom- of haarself met die aksie van die koninklike amptenaar te assosieer.

Die alternatief vir die lesers is om met die inwoners van Jerusalem, wat Jesus as profeet óf verwerp (4:44) óf aanvaar het (7:41) te assosieer. Die evaluerende ideologiese perspektief van die verteller maak so 'n resepsie onwaarskynlik. Die waarskynlike persepsie is eerder dat die lesers hulle van so 'n perspektief sal disassosieer - maar méér nog, ook 'n disassosiasie met die Galileërs wat Jesus hartlik ontvang het, want dan sal dit neerkom op ' $n$ aanvaarding van Jesus as blote "wonderwerker".

Die dominante narratiewe blikhoek in die wyer Johannese narratief is om teenoor geloof wat op bloot die "sien" van wondertekens gebou word, die mens se vertroue eerder te grond in die "aanhoor van woorde". In hierdie verband speel die Geliefde Dissipel ' $n$ belangrike rol wat die Evangelie van Johannes in geheel gesien, betref. In die Johannese gemeenskap was hierdie dissipel klaarblyklik 'n simbool van 'n betroubare tradisie aangaande Jesus se identiteit (vgl Joh 19:35 en 21:34). Hierdie identiteit is, soos ons gesien het, Jesus die Woord (Logos) van God. ${ }^{11}$ Die verteller se dominante blikhoek is dat Jesus se woorde wat onthou word, geglo en vertrou kan word.

\section{Literatuurverwysings}

Bultmann, R [1941] [1964/1966] 1971. The Gospel of John: A commentary, tr by G R Beasley-Murray. Oxford: Blackwell.

Dunn, J D G [1977] 2006. Unity and diversity in the New Testament: An inquiry into the charachter of earliest Christianity. 3rd edition. London: SCM.

Duling, D C \& Perrin, N [1974] 1994. The New Testament: Proclamation and parenesis, myth and history. 3rd edition. Fort Worth, TX: Harcourt Brace College Publishers.

Lindars 1972. The Gospel of John. London: Marshall, Morgan \& Scott.

Martyn, J L 1986. Source criticism and Religionsgeschichte in the Fourth Gospel, in Ashton, J (ed), The interpretation of John, 99-121. Philadelphia, PA: Fortress.

\footnotetext{
${ }^{11}$ Kyk Herman Waetjen (2001), "Logos pros ton Theon and the objectification of truth in the Prologue of the Fourth Gospel”.
} 
Moloney, F J 1980. From Cana to Cana (Jn 2:1-4:54) and the Fourth Evangelist's concept of correct (and incorrect faith), in Livingstone, E A (ed), Studia Biblica 1978. II Papers in the Gospels: Sixt International Congress on Biblical Studies. Oxford 3-7 April 1978, 185-213. Sheffield: JSOT Press. (JSNT.S 2.)

Moloney, F J 1993. Belief in the Word: Reading John 1-4. Minneapolis, MN: Fortress. Moloney, F J 1998. The Gospel of John. Collegeville, MN: The Liturgical Press. (Sacra Pagina Series 4.)

Thatcher, T 2000. The riddles of Jesus in John: A study in tradition and folklore. Atlanta, GA: Society of Biblical Literature. (SBL Monograph Series.)

Van Aarde, A G 1985. Die outeurskapsvraag van die Johannesevangelie met die oog op interpretasie of resepsie. Skrif \& Kerk 6, 45-62.

Van Aarde, A G 1991. Narrative criticism applied to John 4:43-54, in Hartin, P J \& Petzer, J H (eds), Text and interpretation: New approaches in the criticism of the New Testament, 101-128. Leiden: Brill. (New Testament Tools and Studies 15.)

Van Aarde, A G 2006a. Genre en plot georiënteerde narratief-kritiese eksegese van Evangeliemateriaal: Inleiding tot narratiewe kritiek. HTS 62(2), 657-677.

Van Aarde, A G 2006b. Vertellersperspektiefanalise van Nuwe-Testamentiese tekste. HTS 62(3), 1111-1143.

Van Belle, G 1988. The faith of the Galileans: The parenthesis in Jn 4, 44. ETL 74, 27-44.

Van der Watt, J G 2005. Salvation in the Gospel according to John, in Van der Watt, J G (ed), Salvation in the New Testament: Perspectives on soteriology, 101131. Leiden: Brill. (Supplements to Novum Testamentum 121.)

Waetjen, H C 2001. Logos pros ton Theon and the objectification of truth in the Prologue of the Fourth Gospel. CBQ 63, 265-286.

Waetjen, H C 2005. The Gospel of the beloved disciple: A work in two editions. New York: T \& T Clark.

Wegner, U 1985. Der Hauptmann von Kafarnaum (Mt 7,28a; 8,5-10.13 par Lk 7,110): Ein Beitrag zur Q-Forschung. Tübingen: Mohr (Paul Siebeck). (WUNT 2nd Series 14.) 